\title{
AKURASI POTENSI MEMPREDIKSI KEBANGKRUTAN METODE ALTMAN Z-SCORE DAN METODE OHLSON O-SCORE
}

\author{
Indriyana Widyastuti $^{1)}$ \\ Saptani Rahayu ${ }^{2)}$ \\ STIE Adi Unggul Bhirawa Surakarta \\ indriyana_widy@yahoo.co.id
}

\begin{abstract}
ABSTRAK
Penelitian ini bertujuan untuk mengetahui tingkat akurasi prediksi kebangkrutan perusahaan farmasi di Indonesia dengan membandingkan model prediksi Altman Z-Score dengan Olhson dilihat dari aspek kinerja keuangan. Data yang digunakan dalam penelitian ini merupakan data sekunder pada perusahaan farmasi yang terdaftar di Bursa Efek Indonesia (BEI) periode 2013-2016. Pengujian hipotesis menggunakan alat analisis teknik uji beda independent sampel t-test. Hasil pengujian menunjukkan terdapat perbedaan yang signifikan antara kedua model dalam memprediksi potensi kebangkrutan. Hasil akhir penelitian ini menunjukkan bahwa terdapat dua perusahaan yang diprediksi berpotensi mengalami kebangkrutan dengan menggunakan kedua model prediksi Altman dan Ohlson. Kedua perusahaan tersebut adalah PT Indofarma, Tbk., (INAF) dan PT Merck Sharp Dohme Pharma, Tbk., (SCPI). Berdasarkan Model Altman, PT Indofarma, Tbk., (INAF) berpotensi bangkrut pada tahun 2013 dan 2015, dan PT Merck Sharp Dohme Pharma, Tbk., (SCPI) pada tahun 2013 dan 2014, serta pada PT Pyridam Farma Tbk., (PYFA) dalam kategori rawan bangkrut pada tahun 20132016. Berdasarkan Model Ohlson, PT Indofarma, Tbk., (INAF) berpotensi bangkrut pada tahun 2014 dan 2016 , dan PT Merck Sharp Dohme Pharma, Tbk., (SCPI) pada tahun 2015 dan 2016.
\end{abstract}

Kata Kunci: Perusahaan Farmasi, Kebangkrutan, Altman Z-Score, Ohlson

\section{PENDAHULUAN}

Kinerja perusahaan sangat menentukan kemampuan suatu perusahaan untuk dapat bersaing dengan perusahaan lain. Perusahaan yang tidak mampu bersaing untuk mempertahankan kinerjanya lambat laun akan tergusur dari lingkungan industrinya dan akan mengalami kebangkrutan. Agar kelangsungan hidup suatu perusahaan tetap terjaga, maka pihak manajemen harus dapat mempertahankan atau terlebih lagi memacu peningkatan kinerjanya. Secara umum kinerja suatu perusahaan ditunjukkan dalam laporan keuangan yang dipublikasikan (Batubara, 2011:1). Laporan keuangan perusahaan yang diterbitkan setiap periode dapat digunakan sebagai salah satu pengukuran atas kinerja suatu perusahaan. Laporan keuangan merupakan ringkasan dari suatu proses pencatatan atau ringkasan dari transaksitransaksi keuangan yang terjadi selama tahun buku yang bersangkutan (Baridwan, 2010:17).

Kebangkrutan tidak akan terjadi tanpa adanya penyebab kebangkrutan itu sendiri, salah satunya adalah semakin melemahnya kinerja keuangan suatu perusahaan. Berdasarkan penelitian Gamayuni (2011) penyebab kebangkrutan dapat berasal dari faktor internal dan eksternal perusahaan.
Apabila perusahaan mengalami kebangkrutan tentunya ada beberapa pihak yang akan dirugikan yaitu pihak yang memiliki kepentingan terhadap perusahaan seperti investor dan kreditur (Adriana, dkk, 2012). Upaya untuk meminimalisir resiko kebangkrutan, diperlukan suatu alat atau model prediksi yang dapat digunakan untuk memprediksi ada atau tidaknya potensi kebangkrutan perusahaan.

Prediksi kebangkrutan dapat digunakan untuk memberikan panduan bagi pihak-pihak yang berkepentingan terhadap kinerja keuangan perusahaan apakah akan mengalami kesulitan atau tidak dimasa yang akan datang. Bagi pemilik perusahaan dapat digunakan untuk memutuskan apakah tetap mempertahankan kepemilikannya di perusahaan atau menjualnya dan kemudian menanamkan modalnya ditempat lain. Sedangkan bagi investor dan kreditor sebagai pihak eksternal perusahaan dituntut mengetahui perkembangan yang ada dalam perusahaan demi keamanan investasi modalnya. Ketidakmampuan dalam membaca sinyal-sinyal tentang kesulitan usaha, bisa mengakibatkan kerugian terhadap investasi yang sudah dilakukan. 
Secara spesifik penelitian ini berfokus pada akurasi prediksi kebangkrutan perusahaan farmasi yang terdaftar di Bursa Efek Indonesia. Dalam kenyataannya terjadi beberapa fenomena yang dapat mengakibatkan perusahaan mengalami financial distress. Saat ini industri farmasi Indonesia telah dapat memproduksi $90 \%$ kebutuhan produk obat dalam negeri bahkan untuk ekspor. Namun, hampir 95\% produksi tersebut masih bergantung pada Bahan Baku Obat (BBO) impor dari India, Cina, dan Eropa (Tempo.co : 2012). Hal ini sangat mempengaruhi biaya produksi apabila terjadi resesi ekonomi yang melanda negara-negara di belahan dunia seperti American Dollar crisis dan European Euro crisis. Sehingga sewaktu-waktu harga bahan baku dapat melonjak naik apabila terjadi krisis ekonomi di suatu negara dimana perusahaan mengimpor bahan baku tersebut. Permasalahan diatas harus sangat dicermati oleh perusahaan untuk mengantisipasi kesalahan sekecil apapun yang akan berdampak buruk bagi perusahaan sampai akhirnya jatuh bangkrut. Prediksi mengenai gejala-gejala kebangkrutan perusahaan harus dilakukan untuk mengantisipasi terjadinya kebangkrutan di masa yang akan datang. Cara atau model yang dapat dilakukan adalah menganalisis rasio-rasio keuangan perusahaan dengan menggunakan model tertentu salah satunya Model Altman Z-score dan Model Ohlson O-score.

Analisis Z-Score pertama kali dikemukakan oleh Edward I Altman pada tahun 1968 atas penelitian yang dilakukan di Amerika Serikat khusus perusahaan manufaktur yang go public. Tahun 1984 model kebangkrutan tersebut direvisi agar dapat digunakan untuk perusahaan manufaktur privat dan publik. Selanjutnya pada tahun 1995 Altman memodifikasi kembali modelnya agar dapat diterapkan pada semua jenis perusahaan. Menurut Altman (2000), teknik penggunaan MDA (Multiple Discriminant Analysis) mempunyai kelebihan dalam mempertimbangkan karakteristik umum dari perusahaan-perusahaan yang relevan, termasuk interaksi antar perusahaan tersebut. Disamping itu, pendekatan MDA dapat mengkombinasikan berbagai rasio menjadi suatu model prediksi yang berarti dan dapat digunakan untuk seluruh perusahaan, baik perusahaan publik, pribadi, manufaktur, ataupun perusahaan jasa dalamberbagai ukuran. Kelemahan dari model ini adalah tidak ada rentang waktu yang pasti kapan kebangkrutan akan terjadi setelah hasil ZScore diketahui lebih rendah dari standar yang ditetapkan. Model ini juga tidak dapat mutlak digunakan karena adakalanya terdapat hasil yang berbeda jika kita menggunakan obyek yang berbeda.

Berbeda dengan Altman, Ohlson dalam penelitiannya menggunakan analisis logistik untuk menghindari masalah tentang asumsi-asumsi pada Model Multiple Discriminant Analysis (MDA) yang dilakukan Altman, yaitu data yang diuji memerlukan persyaratan normalitas data. Tidak seperti kebanyakan model prediksi yang dilakukan peneliti terdahulu, model ini memasukan variabel ukuran perusahaan sebagai variabel penelitian. Ohlson berasumsi bahwa perusahaan besar memiliki kemungkinan kesulitan keuangan (financial distress) yang lebih kecil karena perusahaan besar biasanya berkembang dan beroperasi dengan baik dan relatif stabil (Lestari : 2014).

\section{METODE PENELITIAN}

Data yang digunakan dalam penelitian ini adalah data sekunder berupa data laporan keuangan tahunan perusahaan farmasi (neraca dan laporan laba rugi) yang telah diaudit tahun 2013 sampai 2015. Perusahaan yang terdaftar di Bursa Efek Indonesia berjumlah 10 perusahaan. Didalam formula perhitungan Model Ohson O-Score juga diperlukan data GNP index Indonesia. Sumber data sekunder yakni laporan keuangan perusahaan farmasi yang digunakan dalam penelitian ini berasal dari website milik Bursa Efek Indonesia yaitu www.idx.co.id. Sedangkan data GNP index Indonesia diperoleh dari www.bps.go.id.

\section{PEMBAHASAN}

Dasar perhitungan untuk memprediksi potensi kebangkrutan perusahaan farmasi yang terdaftar di Bursa Efek Indonesia dapat dihitung dengan formula atau rumus yang telah ditetapkan, serta masing-masing model memiliki nilai cut off sebagai pembatas yang dapat mengklasifikasi perusahaan pada keadaan tertentu yaitu sehat, rawan bangkrut, dan bangkrut. Hasil perhitungan Altman ZScore dalam memprediksi potensi kebangkrutan perusahaan farmasi yang 
terdaftar di Bursa Efek Indonesia (BEI) dengan persamaan :

$\mathrm{Z}=1,2 \mathrm{X}_{1}+1,4 \mathrm{X}_{2}+3,3 \mathrm{X}_{3}+0,6 \mathrm{X}_{4}+1,0 \mathrm{X}_{5}$

Keterangan:

$\mathrm{Z}$ : Overall Indeks (indeks keseluruhan)

$X_{1}$ : Working Capital to Total Assets (Modal

Kerja/Total Aktiva)

$\mathrm{X}_{2}$ : Retained Earning to Total Assets (Laba yang Ditahan/Total Aktiva)

$X_{3}$ : Earning Before Interest and Taxes to Total Assets (Laba Sebelum Bunga dan Pajak/Total Aktiva)

$X_{4}$ : Market Value of Equity to Book Value of Liabilities (Nilai Pasar Modal

Sendiri/Nilai Buku Hutang)

$X_{5}$ : Sales to Total Assets (Penjualan/Total Aktiva)

Analisis kebangkrutan menggunakan Model Altman Z-Score dapat diketahui bahwa jika semakin besar hasil perhitungan Altman Z-Score maka semakin baik kinerja perusahaan atau perusahaan akan dikatakan sehat dan memperoleh kemungkinan terjadinya kebangkrutan yang sangat kecil. Penentuan perusahaan yang masuk kedalam kriteria Sehat, Rawan maupun Bangkrut ditunjukkan pada Tabel 1. Hasil perhitungan Altman Z-Score pada tabel diatas menunjukkan dua perusahaan yang diprediksi mengalami potensi kebangkrutan selama tiga periode perhitungan yaitu PT Indofarma, Tbk., (INAF) dan PT Merck Sharp Dohme Pharma, Tbk., (SCPI). Kedua perusahaan tersebut diprediksi mengalami bangkrut pada periode 2013 dan 2015 untuk INAF dan periode 2013 dan 2014 untuk SCPI. Hasil perhitungan dengan menggunakan Model Z-Score dari kedua perusahaan tersebut dapat diketahui bahwa variabel $X_{1}, X_{2}$ dan $X_{3}$ terhitung sangat kecil. Sedangkan ketiga variabel tersebut sangat mempengaruhi kondisi perusahaan yang bangkrut. Sementara Pyridam Farma Tbk., (PYFA) diprediksi memiliki potensi rawan bangkrut selama periode penelitian 2013-2016.

Variabel $X_{5}$ merupakan variabel yang paling berpengaruh terhadap perhitungan Model Z-Score. Semakin besar nilai $X_{5}$ maka perusahaan mempunyai kinerja keuangan yang baik sehingga nilai yang dihasilkan semakin tinggi dan perusahaan dikategorikan sebagai perusahaan yang sehat. Hasil perhitungan diatas membuktikan bahwa perusahaan yang sehat memiliki nilai $X_{5}$ yang tinggi. Perusahaan yang termasuk kategori sehat yaitu
DVLA, KAEF, KLBF, MERK, SIDO, SQBB, dan TSPC.

Tabel 1. Hasil Perhitungan Altman Z-Score pada Perusahaan Farmasi

\begin{tabular}{|c|c|c|c|c|c|}
\hline No & Nama & $\mathbf{2 0 1 3}$ & $\mathbf{2 0 1 4}$ & $\mathbf{2 0 1 5}$ & $\mathbf{2 0 1 6}$ \\
\hline \multirow{2}{*}{\begin{tabular}{c} 
Perusahaan \\
\cline { 3 - 6 }
\end{tabular}} & DVLA & 7,968614 & 6,704907 & 4,724284 & 4,527539 \\
\hline 2 & INAF & 1,652753 & 2,532986 & 1,781607 & 1,959837 \\
\hline 3 & KAEF & 5,096211 & 6,683406 & 4,439589 & 3,168414 \\
\hline 4 & KLBF & 15,992267 & 22,915385 & 16,990091 & 17,10589 \\
\hline 5 & MERK & 16,995352 & 16,804846 & 15,265606 & 13,89480 \\
\hline 6 & PYFA & 2,320721 & 2,474731 & 2,796233 & 2,819256 \\
\hline 7 & SCPI & 1,120640 & 1,169440 & 2,221529 & 7,047721 \\
\hline 8 & SIDO & 20,91388 & 30,485562 & 26,78854 & 23,46730 \\
\hline 9 & SQBB & 5,053675 & 4,570882 & 4,58765 & 4,68958 \\
\hline 10 & TSPC & 8,718211 & 8,219763 & 6,643023 & 6,738927 \\
\hline
\end{tabular}

Sumber: Laporan keuangan sampel penelitian yang diolah

Keterangan : $\mathrm{Z}>2,99$ (Sehat), 1,81 $<\mathrm{Z}<2,99$

(Rawan Bangkrut), $\mathrm{Z}<1,81$ (Bangkrut)

Hasil perhitungan Ohlson O-Score dalam memprediksi potensi kebangkrutan perusahaan farmasi yang terdaftar di Bursa Efek Indonesia (BEI) dengan persamaan:

$$
\begin{aligned}
\mathrm{O}= & -1,32-0,407 \mathrm{X}_{1}+6,03 \mathrm{X}_{2}-1,43 \mathrm{X}_{3}+ \\
& 0,0757 \mathrm{X}_{4}-2,37 \mathrm{X}_{5}-1,83 \mathrm{X}_{6}+ \\
& 0,285 \mathrm{X}_{7}-1,72 \mathrm{X}_{8}-0,521 \mathrm{X}_{9}
\end{aligned}
$$

Keterangan:

$\mathrm{X}_{1}$ : Log (Total assets / GNP price-level index) (Total aset / GNP)

$\mathrm{X}_{2}$ : Total liabilities / Total assets (Total utang / Total aset) ${ }^{*}$

$\mathrm{X}_{3}$ : Working capital / Total assets (Modal kerja / Total aset) ${ }^{*}$

$\mathrm{X}_{4}$ : Current liabilities / Current assets (Utang lancar / Aset lancar) ${ }^{*}$

$\mathrm{X}_{5}$ : 1 jika total utang $>$ total aset ; 0 jika sebaliknya

$\mathrm{X}_{6}$ : Net income / Total assets (Laba bersih / Total aset)

$\mathrm{X}_{7}$ : Cash flow from operations / Total liabilities (Kas yang tersedia dari kegiatan operasi/total utang)

$\mathrm{X}_{8}$ : 1 jika laba bersih negatif; 0 jika sebaliknya,

$\mathrm{X}_{9}:\left(\mathrm{Nit}_{-} \mathrm{Nit}_{-1}\right) /\left(\mathrm{Nit}+\mathrm{Nit}_{-1}\right)$

Analisis kebangkrutan menggunakan Model Ohlson O-Score dapat diketahui bahwa jika semakin besar hasil perhitungan Ohlson 
O-Score maka semakin buruk kinerja perusahaan atau perusahaan akan dikatakan memperoleh kemungkinan terjadinya kebangkrutan yang besar. Penentuan perusahaan yang masuk kedalam kriteria tidak bangkrut maupun bangkrut ditunjukkan pada table 3 dan 4 . Menurut hasil perhitungan Model Ohlson pada tabel diatas berdasarkan cut off point, skor yang lebih dari 0,38 menunjukkan terdapat dua perusahaan yang mengalami kebangkrutan pada periode 2013 sampai 2016 yaitu PT Indofarma, Tbk., (INAF) dan PT Merck Sharp Dohme Pharma, Tbk., (SCPI). Kedua perusahaan tersebut diprediksi mengalami bangkrut pada periode 2014 dan 2016 untuk INAF serta periode 2015 dan 2016 untuk SCPI. Hasil perhitungan dengan menggunakan Model Ohlson dari kesepuluh perusahaan tersebut dapat diketahui bahwa variable $X_{1}$ dan $X_{7}$ terhitung sangat kecil. Sedangkan kedua variabel tersebut sangat mempengaruhi kondisi perusahaan yang bangkrut.

Perusahaan yang cenderung memiliki nilai rasio likuiditas yang ditunjukan dengan $\left(X_{3}\right.$ dan $\left.X_{4}\right)$ dan rasio profitabilitas $\left(X_{6}\right)$ yang besar, maka perusahaan mempunyai kinerja keuangan yang baik sehingga nilai yang dihasilkan semakin tinggi dan perusahaan dikategorikan sebagai perusahaan yang tidak bangkrut. Perusahaan yang termasuk kategori tidak bangkrut berdasarkan perhitungan Model Ohlson diatas yaitu DVLA, KAEF, KLBF, MERK, PYFA, SIDO, SQBB, dan TSPC.

Tabel 2. Hasil Perhitungan Ohlson O-Score pada Perusahaan Farmasi

\begin{tabular}{|c|c|c|c|c|c|}
\hline $\begin{array}{c}\mathrm{N} \\
\mathrm{o}\end{array}$ & $\begin{array}{c}\text { Nama } \\
\text { Perusaha } \\
\text { an }\end{array}$ & 2013 & 2014 & 2015 & 2016 \\
\hline 1 & DVLA & $-2,296562$ & $-2,328013$ & $-1,965652$ & $-1,89981$ \\
\hline 2 & INAF & $-5,700195$ & 0,719209 & 0,360814 & 0,988114 \\
\hline 3 & KAEF & $-1,378001$ & $-1,083176$ & $-0,709108$ & $-0,08248$ \\
\hline 4 & KLBF & $-1,836904$ & $-1,931079$ & $-1,949283$ & $-2,16225$ \\
\hline 5 & MERK & $-2,510518$ & $-2,489205$ & $-2,614816$ & $-2,54117$ \\
\hline 6 & PYFA & $-0,704353$ & $-0,645050$ & $-1,360729$ & $-1,58071$ \\
\hline 7 & SCPI & 0,145903 & $-1,705534$ & 1,041173 & 1,043265 \\
\hline 8 & SIDO & $-3,341720$ & $-2,933603$ & $-2,804673$ & $-2,81152$ \\
\hline 9 & SQBB & $-2,987798$ & $-2,938347$ & $-2,669478$ & $-2,57255$ \\
\hline 1 & TSPC & $-1,693456$ & $-1,682301$ & $-1,351204$ & $-1,51316$ \\
0 & & & & & \\
\hline
\end{tabular}

Sumber: Laporan keuangan sampel penelitian yang diolah

Keterangan: $\mathrm{O}>0,38$ (Bangkrut), $\mathrm{O}<0,38$ (Tidak Bangkrut)

Uji normalitas data yang digunakan dalam penelitian ini menggunakan Swilk Test (Stata 15). Langkah rekomendasi transformasi digunakan untuk mendapatkan data normal yang terbaik dengan meggunakan histogram sepeti yang ditunjukkan pada Gambar 1 (Rekomendasi transformasi Z-Score) dan Gambar 2 (Rekomendasi transformasi data Oshlon) untuk mendaptkan nilai prob $>$ Chi2 lebih dari 0,05. Berdasarkan hasil rekomendasi tranformasi tersebut, data tranformasi yang terbaik untuk digunakan adalah Cubic untuk Oshlon dan 1/sqrt untuk data Z-Score. Perbedaan rekomendasi transformasi antar variaber tersebut memungkinkan penggunaan data identity. Selain itu, berdasarkan central limit theorm, jumlah observasi dalam penelitian ini juga dapat mengabaikan masalah nomality. Dengan demikian data yang digunakan dalam penelitian ini adalah data identity atau data yang sebelum dilakukan transformasi.

\section{Gambar 1. Rekomendasi transformasi data Z-Score (kiri) dan Oshlon (Kanan)}

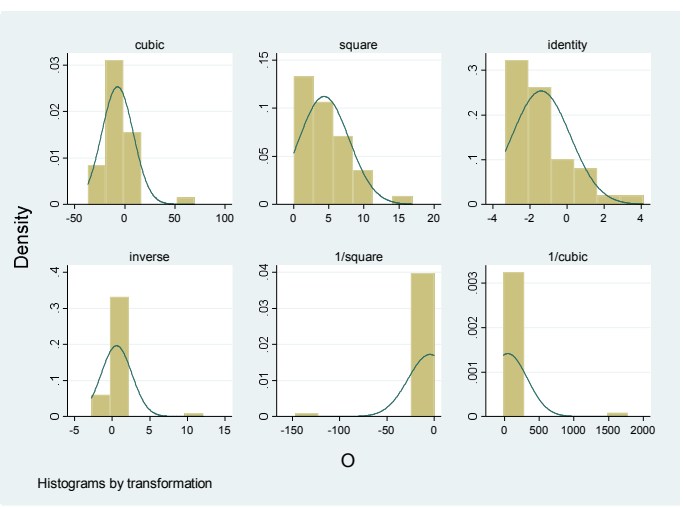

Hipotesis penelitian ini dibuktikan dengan Independent $\mathrm{T}$ test bahwa ada perbedaan signifikan pada prediksi kebangkrutan antara metode Z-Score dan Oshlon. Alat analisis yang digunakan adala independent $t$ test dengan menggunakan program statistik Stata 15. Hasil uji tersebut dapat ditunjukan pada Tabel 5. Tabel tersebut menunjukkan nilai $\operatorname{Pr}($ $\mathrm{T}>\mathrm{t}$ ) kurang dari 0,05. Berdasar hasil tersebut maka dapat disimpulkan bahwa terdapat perbedaan signifikan yang dihitung 
berdasarkan perbedaan mean antara prediksi kebangkrutan antara metode Z-Score dan Oshlon. Tabel perhitungan tingkat akurasi perhitungan Model Altman Z-Score dan Ohlson O-Score dalam memprediksi potensi kebangkrutan Perusahaan farmasi yang terdaftar di Bursa Efek Indonesia (BEI) :

Tabel 7. Perhitungan Tingkat Akurasi Prediksi Kebangkrutan

\begin{tabular}{l|l}
\hline \multicolumn{2}{l}{ Hasil Perhitungan } \\
\hline Kondisi Perusahaan & $\mathrm{B}$ \\
\cline { 2 - 2 } & $\mathrm{S} / \mathrm{TB}$ \\
\hline Total & \\
\hline Total Sampel \\
\hline Akurasi \\
\hline Sumber: Laporan keuangan sampel \\
\end{tabular}

Berdasarkan tabel perhitungan akurasi diatas dapat dilihat bahwa hasil perhitungan dengan menggunakan Model Altman Z-Score mempunyai akurasi 27,5\%, sedangkan perhitungan dengan menggunakan Model Ohlson O-Score mempunyai akurasi $10 \%$. Sehingga dapat disimpulkan bahwa Model Altman Z-Score mempunyai akurasi yang paling tinggi dalam memprediksi potensi kebangkrutan perusahaan farmasi yang terdaftar di Bursa Efek Indonesia.

\section{KESIMPULAN}

Model Altman Z-Score menunjukkan bahwa perusahaan yang berpotensi bangkrut adalah PT Indofarma, Tbk., (INAF) dan PT Merck Sharp Dohme Pharma, Tbk., (SCPI), perusahaan yang masuk dalam kategori rawan adalah Pyridam Farma Tbk., (PYFA), sedangkan perusahaan yang termasuk dalam kategori sehat adalah DVLA, KAEF, KLBF, MERK, SIDO, SQBB, dan TSPC. Perusahaan yang bangkrut diakibatkan nilai rasio likuiditas $\left(X_{1}\right)$ dan profitabilitas yang ditunjukan dengan nilai variabel $\left(X_{2}\right.$ dan $\left.X_{3}\right)$ yang kecil sedangkan perusahaan yang sehat memiliki kemampuan manajemen dalam menggunakan aset untuk menghasilkan penjualan $\left(X_{5}\right)$ yang besar. Model Ohlson $O$ Score menunjukkan perusahaan yang berpotensi bangkrut adalah PT Indofarma,
Tbk., (INAF) dan PT Merck Sharp Dohme Pharma, Tbk., (SCPI), hasil ini serupa dengan hasil dari Model Altman Z-Score. Perusahaan yang mengalami kebangkrutan mempunyai nilai rasio leverage $\left(X_{2}\right)$ yang besar, dimana semakin besar nilai $X_{2}$ maka semakin buruk pula kinerja perusahaan. Perusahaan yang sehat cenderung memiliki nilai rasio likuiditas $\left(X_{3}\right.$ dan $\left.X_{4}\right)$ dan rasio profitabilitas $\left(X_{6}\right)$ yang besar. Perusahaan yang masuk dalam kategori

\begin{tabular}{|l|l|l|l|l|l}
\multicolumn{3}{|c|}{ Z-Score } & \multicolumn{2}{c|}{ O-Score } & \multirow{2}{*}{ Total } \\
\cline { 1 - 5 } B & RB & S & B & TB & \\
\hline 0 & 0 & 0 & 0 & 0 & 0 \\
\hline 4 & 5 & 21 & 2 & 28 & 80 \\
\hline 4 & 5 & 21 & 2 & 28 & 80 \\
\hline 40 & 40 & 80 \\
\hline $2,5 \%$ & $10 \%$ & \\
\hline
\end{tabular}

sehat adalah DVLA, KAEF, KLBF, MERK, PYFA, SCPI, SIDO, SQBB, TSPC.

perbedaan Model Altman Z-Score dan

Model Ohlson O-Score dalam memprediksi kebangkrutan perusahaan Farmasi yang Terdaftar di Bursa Efek Indonesia menunjukkan bahwa nilai $\operatorname{Pr}(\mathrm{T}>\mathrm{t})$ kurang dari 0,05. sehingga Ho ditolak dan $\mathrm{Ha}$ diterima. Artinya terdapat perbedaan yang signifikan antara Model Altman Z-Score dan Ohlson O-Score dalam memprediksi potensi kebangkrutan pada perusahaan farmasi yang terdaftar di Bursa Efek Indonesia. Terdapat kelemahan dan kelebihan diantara kedua model prediksi yaitu 1) berdasarkan perhitungan tingkat akurasi Model Altman ZScore memiliki akurasi lebih tinggi yaitu mencapai 27,5\% dibandingkan Model Ohlson dengan yang hanya memiliki akurasi $10 \%$. Sehingga Model Altman Z-Score merupakan model yang paling efektif digunakan untuk memprediksi potensi kebangkrutan pada perusahaan farmasi yang terdaftar di Bursa Efek Indonesia dan 2) Berdasarkan klasifikasi nilai cut off setiap model prediksi kebangkrutan, Model Altman Z-Score memiliki tiga kriteria dalam mengklasifikasikan perusahaan pada tahap prediksi kebangkrutan yaitu sehat, rawan dan bangkrut. Sedangkan Model Ohlson hanya memiliki dua klasifikasi nilai cut off prediksi yaitu sehat dan bangkrut. Sehingga Model Altman merupakan model yang lebih direkomendasikan untuk para pemakai 
informasi kebangkrutan (stakeholders) dalam hal pengambilan keputusan secara tepat.

\section{DAFTAR PUSTAKA}

Adriana, Azwir Nasir, dan Rusli 2012, Analisis Prediksi Kebangkrutan Menggunakan Metode Springate pada Perusahaan Foods And Beverages Yang Terdaftar di Bursa Efek Indonesia Periode 2006-2010, Skripsi, Fakultas Ekonomi Universitas Riau.

Akhyar, Muhammad Adnan. 2000. Analisis Tingkat Kesehatan Perusahaan Untuk Memprediksi Potensi Kebangkrutan Dengan Pendekatan Altman. Dalam JAAI Vol.4 No. 2 Desember.

Altman, Edward I, 1968, Financial Ratios, Disriminant Analysis and The Prediction of Corporate Bankruptcy, Journal of Fianance, Vol. XXIII No.4 September, pp. 589-609.

Anjum, Sanobar. 2012. Business bankruptcy prediction models: A significant study of the Altman's Z-score model. Asian Journal of Management Research 3(1). Rayalaseema University.

Aprilia Nugraheni. 2005. Analisis Ketepatan Prediksi Potensi Kebangkrutan Melalui Altman Z-Score dan Hubungannya dengan Harga Saham pada Perusahaan Perbankan yang Listing di Bursa Efek Jakarta. Skripsi. Fakultas Ekonomi Universitas Negeri Semarang.

Baridwan, Zaki. 2010. Intermediate Accounting Edisi 8. Yogyakarta: BPFE

Batubara, E.D. 2011. Pengaruh Perubahan Struktur Modal Dan Dividen Pay Out Ratio Terhadap Perubahan Harga Saham Pada Lembaga Keuangan DiBursa Efek Indonesia. Tesis akuntansi. Universitas Sumatera Utara. Medan.

Beaver, William H, 1966, Financial Ratios as Predictors of Failure, Empirical Research in Accounting, Selected Studies and discussion by Preston K Mears and by John Neter, pp. 71-127.

Burhanuddin, Rizky A. 2015. Analisis Penggunaan Metode Altman Z-Score Dan Metode Springate Untuk Mengetahui Potensi Terjadinya Financial Distress Pada Perusahaan Manufaktur Sektor Industri Dasar Dan
Kimia Sub Sektor Semen Periode 2009-2013 (Skripsi). Makasar : Universitas Hasanuddin.

Darsono dan Ashari. 2005. Pedoman praktis memahami laporan keuangan. Andi. Yogyakarta.

Fatmawati, Mila. 2012. Penggunaan The Zmijewski Model, The Altman Model, Dan The Springate Model Sebagai Prediktor Delisting. Jurnal Keuangan Dan Perbankan 16(1), h:56-65. Fakultas Ekonomi Universitas Muhammadiyah Metro.

Gamayuni, Rindu Rika 2011, Analisis Ketepatan Model Altman Sebagai Alat untuk Memprediksi Kebangkrutan (Studi Empiris pada Perusahaan Manufaktur di BEI). Jurnal Akuntansi dan Keuangan,Vol 16 No.2, h. 176190.

Ghozali, Imam. 2005. Aplikasi Analisis Multivariate dengan Program SPSS. Semarang : Badan Penerbit UNDIP

Hadi, A., \& Anggraeni, A. (2008). Pemilihan Prediktor Delisting Terbaik (Perbandingan antara The Zmijewski Model, The Altman Model, dan The Springate Model). Jurnal Akuntansi dan Auditing Indonesia, Vol. 12 No.2.

Hanafi M. Mamduh, dan Halim Abdul. 2003. Analisis laporan keuangan. Unit Penerbit dan Percetakan AMP-YKPN. Yogyakarta.

Harahap, Sofyan Syafri. 2008. Analisis Kritis atas Laporan Keuangan. PT. Raja Grafindo Persada : Jakarta.

Hayes, Suzanne K. Kay A. Hodge and Larry W. Hughes. 2010. "A Study of the Efficacy of Altman's Z To Predict Bankruptcy of Specialty Retail FirmsDoing Business in Contemporary Times". Economics \& Business Journal: Inquiries \& Perspectives 3(1). University of Nebraska at Kearney and Central Washington University.

Hidayat, Gustina. 2015. Analisis Dalam Memprediksi Kebangkrutan Dengan Menggunakan Multiple Discriminant Analysis Dan Logit Pada Industri Farmasi Yang Terdaftar Di Bursa Efek Indonesia Periode 2009-2014. Tesis. Universitas Telkom. Bandung. 
IAI. 2009. Standar Akuntansi Keuangan. Jakarta: Salemba Empat

Ikatan Akuntan Indonesia. 2007. Pernyataan Standar Akuntansi Keuangan (PSAK). Jakarta.

Kieso Donald E. 2011. Accounting Principles (Pengantar Akuntansi) Edisi 7 Buku 1 dan2. Jakarta: Salemba Empat

Lestari, Sri. 2014. Analisis Pengaruh Rasio Keuangan dalam Memprediksi Perubahan Laba pada Perusahaan BUMN yang Terdaftar di BEI Periode 2007-2011. Skripsi. Surakarta : Fakultas Ekonomi Universitas Muhammadiyah Surakarta.

Lili Syafitri dan Trisnadi Wijaya. 2014. Analisis Komparatif Dalam Memprediksi Kebangkrutan Pada Pt. Indofood Sukses Makmur Tbk. Palembang: STIE MDP

Martin, et al, (1995) Kebangkrutan dalam: Kuliah Akuntansi : 376 http://dwiermayanti.wordpress.com/20 11/06/10/kebangkrutan/

Martono dan Agus Harjito. 2010. Manajemen Keuangan, (Edisi 3). Yogyakarta : Ekonisia.

Munawir, Slamet. 2000. Analisa laporan Keuangan, Edisi Revisi liberty. Cetakan Keenam. Ghalia Indonesia: Jakarta.

Odipo M.K. and Sitati, A. 2010. Evaluation Of Applicability Of Altman's Revised Model in Prediction Of Financial Distress: A Case Of Companies Quoted in The Nairobi Stock Exchange. Journal of Business Failure Prediction.

Ohlson, James A,1980, Financial Ratios and The Probabilistic Prediction of Bankrupty, Journal of Accounting research, vol. 18 No. 1 Spring, pp. 109-131

Prihadi, Toto. 2010. Analisis Laporan Keuangan. Jakarta: PPM

Rahardjo Budi. 2007. Keuangan dan Akuntansi, Edisi Pertama. Cetakan Pertama. Graha Ilmu, Yogyakarta.

Rudianto. 2013. Akuntansi Manajemen. Jakarta: Erlangga

Simamora, Henry. 2002. Akuntansi Basis Pengambilan Keputusan Bisnis. Jilid Dua. Cetakan Pertama. Penerbit Salemba Empat. Jakarta.
Sugiono dan Eri Wibowo. 2004. Statistika Untuk Penelitian. Bandung: Alfabeta

Toto, Prihadi. 2011. Analisis laporan keuanagn teori dan aplikasi. PPM. Jakarta.

Udchiah, Yuni. 2013. Model Analisis Zmijewski (X-Score), Ohlson (Y-Score) Dan Altman (Z-Score) Sebagai Indikator Pengukuran Financial Distress (Studi Pada Perusahaan Manufaktur Yang Go Public Di BEI Periode 2008- 2011)(Skripsi).

Malang : Universitas Islam Negeri Malik Ibrahim.

Weston J. Fred dan Brigham Euege F. (2006). Manajemen Keuangan. Jakarta: Erlangga

www.bps.go.id

www.idx.co.id

www.repository.stiesia.ac.id www.republika.com.id

www.tempo.com 